\title{
Efficacy and safety of ascending doses of praziquantel against Schistosoma haematobium infection in preschool-aged and school-aged children: a single-blind randomised controlled trial
}

\author{
Jean T. Coulibaly ${ }^{1,2,3}$, Gordana Panic ${ }^{1,2}$, Richard B. Yapi ${ }^{4}$, Jana Kovač ${ }^{1,2}$, Beatrice Barda ${ }^{1,2}$, Yves K. N'Gbesso ${ }^{5}$,
} Jan Hattendorf ${ }^{2,6}$ and Jennifer Keiser ${ }^{1,2^{*}}$

\begin{abstract}
Background: Despite decades of experience with praziquantel treatment in school-aged children (SAC) and adults, we still face considerable knowledge gaps relevant to the successful treatment of preschool-aged children (PSAC). This study aimed to assess the efficacy and safety of escalating praziquantel dosages in PSAC infected with Schistosoma haematobium.

Methods: We conducted a randomised, dose-finding trial in PSAC (2-5 years) and as comparator a cohort of SAC (6-15 years) infected with S. haematobium in Côte d'Ivoire. A total of 186 PSAC and 195 SAC were randomly assigned to 20,40 or $60 \mathrm{mg} / \mathrm{kg}$ praziquantel or placebo. The nature of the dose-response relationship in terms of cure rate (CR) was the primary objective. Egg reduction rate (ERR) and tolerability were secondary outcomes. CRs and ERRs were assessed using triplicate urine filtration over 3 consecutive days. Available-case analysis was performed including all participants with primary endpoint data.

Results: A total of 170 PSAC and 174 SAC received treatment. Almost 90\% of PSAC and three quarters of SAC were lightly infected with S. haematobium. Follow-up data were available for 157 PSAC and 166 SAC. In PSAC, CRs of praziquantel were $85.7 \%$ (30/35), 78.0\% (32/41) and 68.3\% (28/41) at 20, 40 and $60 \mathrm{mg} / \mathrm{kg}$ and $47.5 \%$ (19/40) for placebo. In SAC, CRs were 10.8\% for placebo (4/37), 55.6\% for $20 \mathrm{mg} / \mathrm{kg}$ (25/45), $68.3 \%$ for $40 \mathrm{mg} / \mathrm{kg}(28 / 41)$ and $60.5 \%$ for $60 \mathrm{mg} /$ $\mathrm{kg}(26 / 43)$. ERRs based on geometric means ranged between $96.5 \%(60 \mathrm{mg} / \mathrm{kg})$ and $98.3 \%(20 \mathrm{mg} / \mathrm{kg})$ in PSAC and between $97.6 \%(20 \mathrm{mg} / \mathrm{kg}$ and $60 \mathrm{mg} / \mathrm{kg})$ and $98.6 \%(40 \mathrm{mg} / \mathrm{kg})$ in SAC. Adverse events were mild and transient.
\end{abstract}

Conclusions: Praziquantel revealed dose-independent efficacy against light infections of $\mathrm{S}$. haematobium. Over the dose range tested, praziquantel displayed a ceiling effect with the highest response for $20 \mathrm{mg} / \mathrm{kg}$ in PSAC. In SAC maximum efficacy was obtained with $40 \mathrm{mg} / \mathrm{kg}$ praziquantel. Further investigations are required in children with moderate to heavy infections.

Trial registration: This trial is registered with International Standard Randomised Controlled Trial Number ISRCTN15280205.

Keywords: Efficacy, Praziquantel, Preschool-aged children, Schistosoma haematobium, School-aged children

\footnotetext{
* Correspondence: jennifer.keiser@swisstph.ch

1Department of Medical Parasitology and Infection Biology, Swiss Tropical

and Public Health Institute, P.O. Box, CH-4002, Basel, Switzerland

${ }^{2}$ University of Basel, Basel, Switzerland

Full list of author information is available at the end of the article
}

(c) The Author(s). 2018 Open Access This article is distributed under the terms of the Creative Commons Attribution 4.0 International License (http://creativecommons.org/licenses/by/4.0/), which permits unrestricted use, distribution, and reproduction in any medium, provided you give appropriate credit to the original author(s) and the source, provide a link to the Creative Commons license, and indicate if changes were made. The Creative Commons Public Domain Dedication waiver (http://creativecommons.org/publicdomain/zero/1.0/) applies to the data made available in this article, unless otherwise stated. 


\section{Background}

Schistosomiasis is a major public health problem with an estimated 779 million people at risk of infection [1]. The disease is caused by trematode worms of the genus Schistosoma, where infection with Schistosoma japonicum and S. mansoni causes mostly intestinal schistosomiasis, while S. haematobium is responsible for genitourinary schistosomiasis [2-6]. Cumulative schistosome infections over years, due to rapid reinfection, result in morbid sequelae, including haematuria, nutritional deficiencies, anaemia, hepatic peri-portal fibrosis and consequent portal hypertension and delayed physical and cognitive development [7-9]. Moreover, genitourinary schistosomiasis can lead to obstruction and carcinomas of urogenital organs and impairment to female reproductive health $[6,10]$. To control schistosomiasis morbidity, health authorities rely on mass administration (preventive chemotherapy) of praziquantel in school-aged children (SAC), the population most affected [11-13]. In 2010, the World Health Organization (WHO) endorsed the inclusion of preschool-aged children (PSAC) in preventative chemotherapy programmes, since there is increasing evidence that they are also affected by schistosomiasis and could suffer from morbidity [14-17]. In the absence of an appropriate paediatric formulation, broken or crushed praziquantel tablets are commonly used in PSAC using the standard $40 \mathrm{mg} / \mathrm{kg}$ dose [18]. A range of studies showed that this dose was well tolerated and efficacious $[15,19,20]$. However, the heterogeneity of methodology and reporting on praziquantel efficacy and safety assessment make decision-making difficult [21].

In the paediatric population, growth and maturation of organs are dynamic. Changes in body proportion and metabolism occur throughout infancy and childhood that affect how drugs are metabolised [22, 23]. Well-designed paediatric drug trials are therefore warranted in order to guide the proper usage of drug treatments to avoid underdosing, overdosing, ineffectiveness and safety problems.

We recently conducted a randomised, controlled dose-finding study assessing the safety and efficacy of praziquantel in PSAC and SAC infected with S. mansoni. Considerable differences were observed between these two age groups with regard to efficacy. For example, while treatment of SAC with 40 or $60 \mathrm{mg} / \mathrm{kg}$ met the WHO standards of clinical efficacy of $\geq 90 \%$ egg reduction rate (ERR) based on arithmetic mean (AM), none of the doses administered could reach this threshold in PSAC [24].

This study was designed to support the ongoing efforts to successfully control schistosome infections in PSAC by assessing the efficacy and safety of escalating praziquantel dosages in PSAC compared to SAC infected with $S$. haematobium. The clinical evidence for praziquantel obtained for both S. haematobium and S. mansoni in PSAC will facilitate the clinical decision-making process, resulting in successful control of schistosome infection and disease.

\section{Methods \\ Study design and participants}

We conducted a randomised, parallel-group, single-blind, placebo-controlled, dose-ranging trial between November 2015 and February 2016. PSAC (aged 2-5 years) and SAC (6-15 years) were surveyed in five villages of the health district of Adzopé, southern Côte d'Ivoire. In total, 740 PSAC and 444 SAC were registered during the census and were invited to participate in the study.

\section{Randomisation and masking}

Eligibility of children was based on the presence of S. haematobium eggs in their urine. In addition, a clinical examination and an oral medical history by active questioning were implemented in order to exclude children with abnormal medical conditions (i.e. clinical malaria or hepato-splenic schistosomiasis) or those who received an antimalarial or anthelmintic drug in the past 4 weeks.

S. haematobium egg-positive PSAC and SAC, eligible for the study, were stratified according to baseline infection intensity into light $(<50 \mathrm{eggs} / 10 \mathrm{~mL}$ of urine) or heavy ( $\geq 50$ eggs $/ 10 \mathrm{~mL}$ of urine) infection intensities [25]. Children were then randomly assigned to placebo or 20,40 or $60 \mathrm{mg} / \mathrm{kg}$ praziquantel treatment arms using computer-generated stratified block randomisation codes provided by an independent statistician based on the aforementioned infection intensity (block size of 8). Only the investigator dealing with drug administration was aware of the treatment assignments. The physician and laboratory technicians were blinded to the treatment. SAC might have recognised the treatment dose due to the number of tablets administered; however, the crushing of tablets for PSAC was prepared in advance. Masking was maintained throughout the trial. Randomisation codes were released after the database was unlocked.

\section{Field and laboratory procedures}

During the baseline survey, three urine samples over 3 consecutive days and a single stool sample from the first collection day were collected between 10:00 and 14:00 am from each participating child. Urine and stool samples were transferred to a nearby laboratory in Azaguié town and examined on the day of collection. S. haematobium was detected using the urine filtration method (syringe filtration of $10 \mathrm{~mL}$ of urine followed by microscopic examination of the filter) [26]. A subsequent independent quality control of sample results (approximately 10\%) was conducted. If a difference in presence/absence of $S$. haematobium eggs was observed or egg counts exceeded $+/-10$ eggs for light infections or $+/-20$ eggs for heavy infections, all the slides were read 
once again by the senior technician. S. mansoni infection was assessed through duplicate Kato-Katz thick smears (standard template of $41.7 \mathrm{mg}$ ) [27]. Eggs of soil-transmitted helminths, i.e. Ascaris lumbricoides, hookworm and Trichuris trichiura, were also assessed and recorded for each parasite species separately. Moreover, finger prick blood samples were taken to assess Plasmodium infections and haemoglobin amount using, respectively, thick and thin blood smears [24] and a calibrated HemoCue device (HemoCue 301 system, HemoCue, Ängelholm, Sweden).

To assess treatment efficacy, another three urine samples and a single stool sample were collected between 21 and 25 days post-treatment and subjected to the same diagnostic approaches applied at baseline. At the end of the study, all children enrolled in the study were offered albendazole (400 mg) and praziquantel $(40 \mathrm{mg} / \mathrm{kg}$ ) for the treatment of helminth infections according to local guidelines.

\section{Treatment}

Prior to treatment, each child received breakfast. In both study groups (SAC and PSAC), treatment was done based on the child's body weight (graduated increments of $0.1 \mathrm{~kg}$ ). Praziquantel $\left(600 \mathrm{mg} \mathrm{Cesol}{ }^{\circ}\right.$ ) (used in quarter-tablet increments) and placebo were obtained from Merck KGaA, Darmstadt, Germany and Fagron, Barsbüttel, Germany, respectively. For PSAC, tablets were crushed using a mortar and pestle and dissolved in a small volume of syrup-flavoured water to mask the taste. SAC and the mothers/guardians of PSAC were interviewed 3, 24, 48 and $72 \mathrm{~h}$ after treatment for adverse events and the intensities graded by the study physician as mild, moderate, severe or intolerable [24].

\section{Outcomes and sample size determination}

The cure rate (CR) (primary outcome) was expressed as the proportion of children positive for S. haematobium eggs at baseline survey who became negative at follow-up. The secondary outcomes were ERR and the safety of different doses of praziquantel.

Simulations showed that with 40 children enrolled per treatment arm $(0,20,40$ and $60 \mathrm{mg} / \mathrm{kg})$, the dose-response prediction model should have a median precision-defined as one half length of the $95 \%$ confidence interval (CI) - of $10 \%$ points, assuming associated cure rates of $2.5 \%, 50 \%$, $75 \%[28]$ and $90 \%$.

\section{Statistical analysis}

All data were first double entered into an Excel spreadsheet, then transferred into Epi Info version 3.5.2 (Centers for Disease Control and Prevention, Atlanta, GA, USA) and cross-checked. $\mathrm{R}$ version 3.4.0 was used for all statistical analyses. Available-case analysis was implemented including all treated participants (regardless of whether they could swallow the drug or not or were wrongly dosed) who had at least one urine sample examined with the urine filtration method at follow-up and were not excluded due to a medical condition.

In order to calculate ERR, the AM and geometric mean (GM) of eggs per $10 \mathrm{~mL}$ of urine before and after treatment were assessed. Geometric mean egg counts were calculated as follows: $\mathrm{e}^{1 / \mathrm{n} \Sigma \log (\mathrm{x}+1)}-1$, and the corresponding ERR ([1 - geometric mean egg output after treatment/geometric mean egg output at baseline] $\times 100$ ) was assessed. A bootstrap resampling method with 5000 replicates was used to estimate $95 \%$ CIs for ERRs.

$E_{\max }$ models using the DoseFinding package (version 0.9-14) of the statistical software environment R (v3.3.0) were implemented to predict the dose-response curves in terms of CRs and ERRs. Logistic regression was used to predict $\mathrm{CR}$ by infection intensity at baseline.

\section{Results}

Study flow and baseline characteristics

Overall, 1184 children were invited to participate in the study (Fig. 1). At baseline, 628 PSAC and 356 SAC were screened for S. haematobium infection. Of these, 186 (29.6\%) PSAC and 195 (45.7\%) SAC had a detectable $S$. haematobium infection and were randomised for treatment. On the treatment day, 16 PSAC and 21 SAC were absent. PSAC received $20 \mathrm{mg} / \mathrm{kg}(n=40), 40 \mathrm{mg} / \mathrm{kg}$ $(n=44)$ or $60 \mathrm{mg} / \mathrm{kg}(n=44)$ praziquantel or placebo $(n=42)$. SAC were likewise allocated to $20 \mathrm{mg} / \mathrm{kg}(n=$ $46), 40 \mathrm{mg} / \mathrm{kg}(n=46)$ or $60 \mathrm{mg} / \mathrm{kg}$ praziquantel $(n=44)$ or placebo $(n=38)$. Two PSAC and one SAC were not able to swallow the drug. One PSAC and one SAC were wrongly dosed $(62.5 \mathrm{mg} / \mathrm{kg}$ instead of $40 \mathrm{mg} / \mathrm{kg}$ and $75 \mathrm{mg} / \mathrm{kg}$ instead of $40 \mathrm{mg} / \mathrm{kg}$, respectively).

At follow-up, data were available for 157 PSAC and 166 SAC. One PSAC and 12 SAC provided only two urine samples, while one SAC provided only one urine sample.

The median age, weight, height and sex of PSAC and SAC were balanced among the treatment groups (Table 1). Three quarters of PSAC and SAC were lightly infected with $S$. haematobium. No infection with $A$. lumbricoides, $T$. trichiura or hookworm was recorded. Co-infections among $S$. haematobium-infected children with S. mansoni and P. falciparum were very low (less than 9\%) in PSAC and SAC. Median haemoglobin values ranged between 10.5 and $11.0 \mathrm{~g} / \mathrm{dL}$ in PSAC and between 11.0 and $11.7 \mathrm{~g} / \mathrm{dL}$ in SAC.

\section{Efficacy of praziquantel}

The nature of the dose response based on CRs is depicted in Fig. 2. Praziquantel revealed dose-independent efficacy 


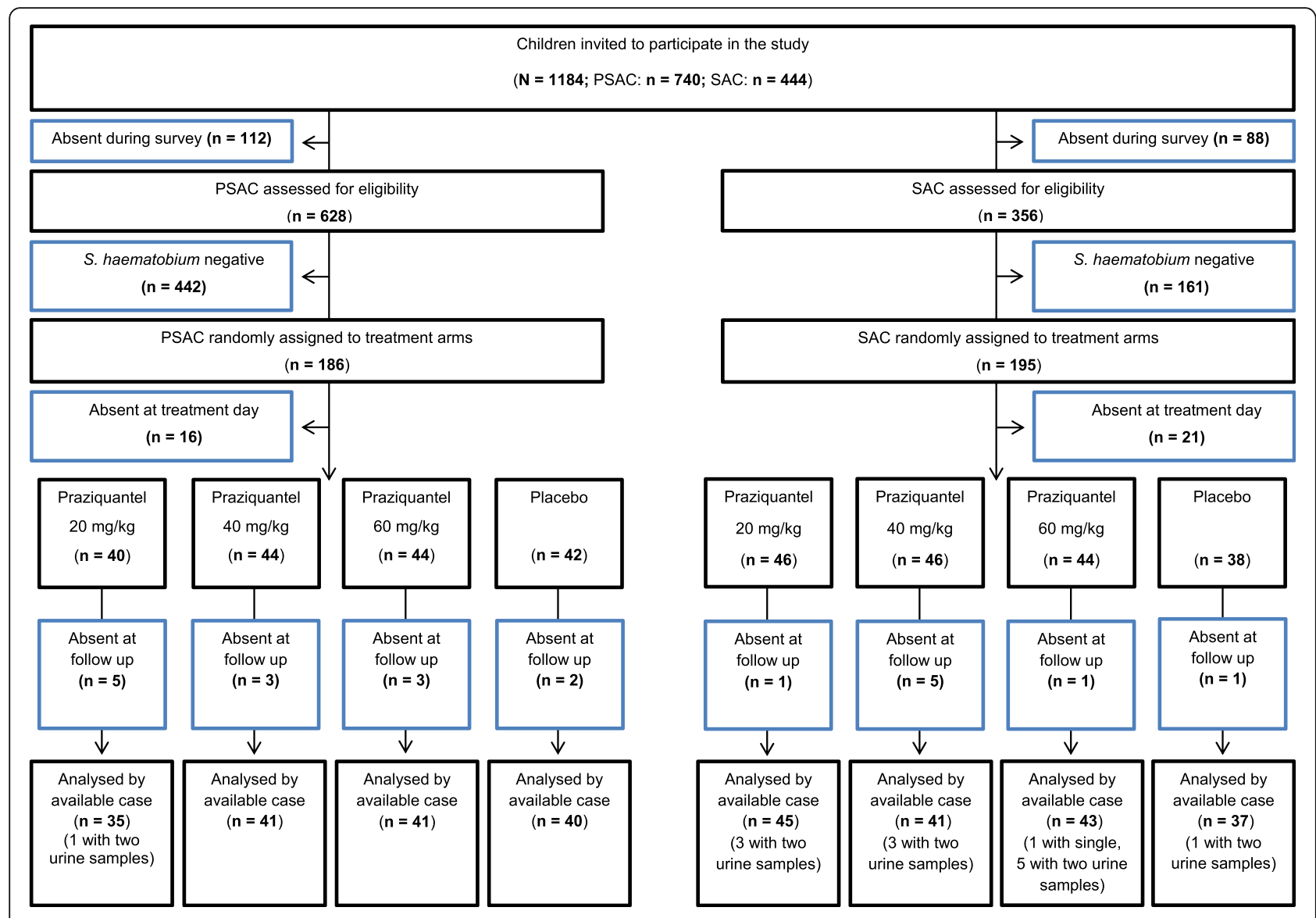

Fig. 1 Trial profile

with the highest cure rates observed at 20 and $40 \mathrm{mg} /$ $\mathrm{kg}$ in PSAC and SAC, respectively. The $E_{\max }$ model based on actual doses on the per protocol population is presented in Additional file 1: Figure S1 and shows a similar trend. Additional file 1: Figure S2 presents the predicted probability of being cured by baseline infection intensity. For all treatments, including placebo, there was a high probability of being cured at low infection intensities.

CRs in PSAC for $20 \mathrm{mg} / \mathrm{kg}, 40 \mathrm{mg} / \mathrm{kg}$ and $60 \mathrm{mg} / \mathrm{kg}$ were 85.7 (95\% CI 69.7-95.2), 78.0\% (95\% CI 62.4-89.4) and $68.3 \%$ (95\% CI 51.9-81.9), respectively, whereas in SAC the respective CRs were $55.6 \%$ (95\% CI 40.0-70.4), 68.3\% (95\% CI 51.9-81.9) and 60.5\% (95\% CI 44.4-75.0). In the placebo groups, $S$. haematobium eggs were not detected in the urine samples of $47.5 \%$ (19/40) and $10.8 \%(4 / 37)$ in PSAC and SAC, respectively (Table 2). Imputation of missing data with treatment failure or success in the intention-to-treat analysis did not change the observed outcomes (Additional file 1: Table S1).

ERRs are summarized in Table 2 and depicted in Fig. 3. ERRs in PSAC were $98.3 \%$ for $20 \mathrm{mg} / \mathrm{kg}$, $97.6 \%$ for $40 \mathrm{mg} / \mathrm{kg}$ and $96.5 \%$ for $60 \mathrm{mg} / \mathrm{kg}$. In SAC ERRs of
97.6\%, 98.6\% and $97.6 \%$ were observed with increasing dosages. ERRs based on AMs had similar profiles to those based on GMs and are presented in Table 2. Table 2 also presents an exploratory subgroup analysis on CRs according to $S$. haematobium infection intensity. The CR in PSAC ranged from $73.0 \%(60 \mathrm{mg} / \mathrm{kg})$ to $87.9 \%(20 \mathrm{mg} / \mathrm{kg})$ in light infections and from $25.0 \%(60 \mathrm{mg} / \mathrm{kg})$ to $66.7 \%(40 \mathrm{mg} / \mathrm{kg})$ in heavy infections. In SAC, CRs were $70.6 \%(20 \mathrm{mg} / \mathrm{kg})$ to $78.8 \%$ $(40 \mathrm{mg} / \mathrm{kg})$ for light $S$. haematobium infections and between $9.1 \%(20 \mathrm{mg} / \mathrm{kg})$ and $27.3 \%(60 \mathrm{mg} / \mathrm{kg})$ for heavy infections.

\section{Safety of praziquantel}

Adverse events data were available for 168 PSAC and 173 SAC (Table 3). In both groups, more children reported signs and symptoms at pre-treatment compared to 3 and $24 \mathrm{~h}$ post-treatment. No serious adverse events were reported. Overall, adverse events were mild with fewer adverse events observed at $3 \mathrm{~h}$ post-treatment compared to pre-treatment in PSAC (52 episodes versus 88 episodes) and in SAC (88 episodes versus 92 episodes), respectively. Mild events mainly included fever, 
Table 1 Baseline characteristics

\begin{tabular}{|c|c|c|c|c|c|c|c|c|}
\hline \multirow[b]{3}{*}{ Characteristics } & \multicolumn{4}{|c|}{ Preschool-aged children (PSAC) } & \multicolumn{4}{|c|}{ School-aged children (SAC) } \\
\hline & \multicolumn{4}{|c|}{ Treatment arm } & \multicolumn{4}{|c|}{ Treatment arm } \\
\hline & Placebo & $20 \mathrm{mg} / \mathrm{kg}$ & 40 mg/kg & 60 mg/kg & Placebo & $20 \mathrm{mg} / \mathrm{kg}$ & 40 mg/kg & 60 mg/kg \\
\hline & 42 & 40 & 44 & 44 & 38 & 46 & 46 & 44 \\
\hline Female N (\%) & $23(54.8)$ & $21(52.5)$ & $20(45.5)$ & $27(61.4)$ & $23(60.5)$ & $25(54.3)$ & $25(54.3)$ & $25(56.8)$ \\
\hline Age, years; median & 4 & 4 & 4 & 4 & 9 & 8 & 8 & 9 \\
\hline$[\mathrm{QQR}]$ & {$[2-5]$} & {$[2-5]$} & {$[2-5]$} & {$[2-5]$} & {$[6-13]$} & {$[6-13]$} & {$[6-14]$} & {$[6-13]$} \\
\hline Weight, kg; median & 15 & 15 & 15 & 15 & 22 & 22 & 24 & 22 \\
\hline$[\mathrm{QQR}]$ & [10-21] & [11-19] & [11-19] & [11-18] & [18-35] & [18-33] & [18-38] & [18-40] \\
\hline Height, cm; median & 97 & 98 & 101 & 100 & 125 & 125 & 125 & 124 \\
\hline$[\mathrm{QQR}]$ & {$[80-117]$} & [83-115] & [84-116] & [83-114] & [109-141] & [114-139] & [113-149] & [112-150] \\
\hline Haemoglobin (g/dL); median & 10.5 & 11.0 & 10.9 & 10.9 & 11.4 & 11.2 & 11.7 & 11.6 \\
\hline$[\mathrm{QQR}]$ & {$[9.1-13.2]$} & {$[9.1-12.8]$} & {$[8.8-12.5]$} & {$[8.5-12.9]$} & {$[9.7-13.7]$} & {$[9.9-12.4]$} & {$[9.7-12.8]$} & {$[10.1-13.5]$} \\
\hline \multicolumn{9}{|l|}{ Infection intensity N (\%) } \\
\hline Light & $36(85.7)$ & $38(95.0)$ & $38(86.4)$ & $40(90.9)$ & $27(71.1)$ & $35(76.1)$ & $36(78.3)$ & $33(75.0)$ \\
\hline Heavy & $6(14.3)$ & $2(5.0)$ & $6(13.6)$ & $4(9.1)$ & $11(28.9)$ & $11(23.9)$ & $10(21.7)$ & $11(25.0)$ \\
\hline \multicolumn{9}{|l|}{ Co-infections N (\%) } \\
\hline S. mansoni & $0(0.0)$ & $0(0.0)$ & $1(2.3)$ & $1(2.3)$ & $0(0.0)$ & $1(2.2)$ & $1(2.2)$ & $0(0.0)$ \\
\hline Plasmodium falciparum & $1(2.4)$ & $0(0.0)$ & $1(2.3)$ & $0(0.0)$ & $1(2.6)$ & $4(8.7)$ & $2(4.3)$ & $3(6.8)$ \\
\hline (based on thin/thick smear) & & & & & & & & \\
\hline
\end{tabular}

$I Q R$ interquartile range

headache, nausea, diarrhoea, vomiting, dizziness and stomach ache. Few moderate cases were reported at $3 \mathrm{~h}$ after treatment in PSAC (only one with moderate diarrhoea $)$ and in SAC $(n=12)$. At $24 \mathrm{~h}$ post-treatment, 25 (14.9\%) and $47(27.2 \%)$ adverse events were recorded in PSAC and SAC, respectively. For both age groups the number of adverse events was similar among the three praziquantel treatment arms,

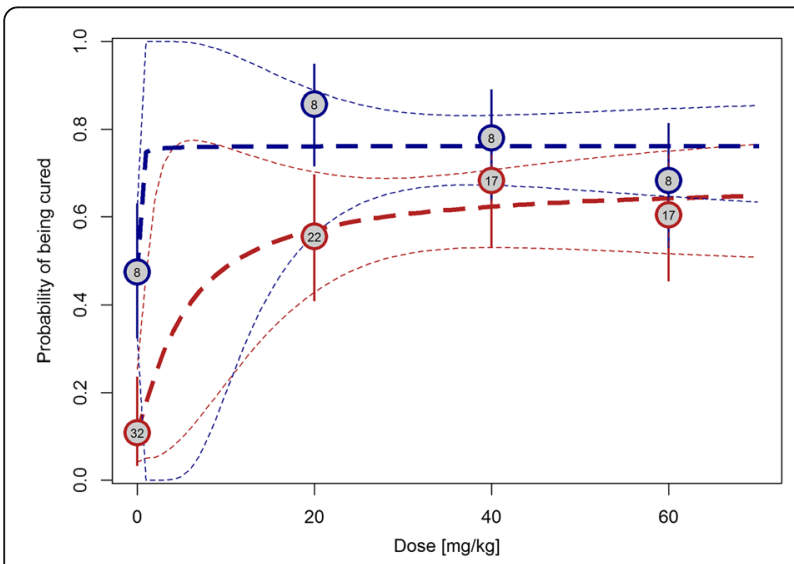

Fig. 2 Cure rates in PSAC (blue lines) and SAC (red lines). Circles show observed cure rates with $95 \% \mathrm{Cls}$ (vertical lines). Numbers in the circles show geometric mean infection intensities at baseline (BL). Dashed lines represent the estimated dose-response curve and corresponding 95\% Cls predicted by the $E_{\max }$ models. Geometric mean of infection intensity was the mean of eggs filtered from $10 \mathrm{~mL}$ of urine with fewer adverse events observed in the placebo-treated groups. The most common adverse events in PSAC and SAC $24 \mathrm{~h}$ post-treatment were diarrhoea (4.8 and 3.5\%), stomach ache (3.6 and 9.8\%), fever (6.0 and 13.3\%), headache (3.0 and 15.6\%) and nausea (2.4 and 6.9\%).

\section{Discussion}

Over the past decade, preventive chemotherapy programmes for the control of schistosomiasis targeting SAC have scaled up across many countries in tropical and subtropical areas. Great progress has been made in decreasing the burden of this disease [29-31]. However, recent modelling and health economic studies found that expanded community-wide preventive chemotherapy that includes adolescents, adults and PSAC would better reduce the overall disease burden, rates of transmission and reinfection [32].

It was recommended in 2010 that PSAC should be included in preventive chemotherapy programmes [33] using an adequate dose, though this age group is still lacking a suitable formulation. A paediatric formulation of praziquantel (small, orally dispersible tablets) is under development (https://www.pediatricpraziquantelconsortium .org/node/28), but it will take several more years until the drug is marketed and available to all PSAC. To be able to treat preschoolers safely and effectively, we studied ascending doses of praziquantel in PSAC and SAC infected 
Table 2 Available-case analysis of cure and egg reduction rates of 20, 40 and 60 mg/kg praziquantel versus placebo against urogenital schistosomiasis in PSAC and SAC based on the urine filtration method

\begin{tabular}{|c|c|c|c|c|c|c|c|c|}
\hline & \multicolumn{4}{|c|}{ Preschool-aged children (PSAC) } & \multicolumn{4}{|c|}{ School-aged children (SAC) } \\
\hline & Placebo & $20 \mathrm{mg} / \mathrm{kg}$ & $40 \mathrm{mg} / \mathrm{kg}$ & $60 \mathrm{mg} / \mathrm{kg}$ & Placebo & 20 mg/kg & $40 \mathrm{mg} / \mathrm{kg}$ & $60 \mathrm{mg} / \mathrm{kg}$ \\
\hline Infected children before treatment $(N)$ & 40 & 35 & 41 & 41 & 37 & 45 & 41 & 43 \\
\hline Actual dose administered (range; mg/kg) & - & $13.6-25$ & $34.6-62.5^{\mathrm{a}}$ & $50-70$ & - & $16.7-23.7$ & $36.4-75^{b}$ & $56.3-65.6$ \\
\hline Cured children after treatment $N(\%)$ & $19(47.5)$ & $30(85.7)$ & $32(78.0)$ & $28(68.3)$ & $4(10.8)$ & $25(55.6)$ & $28(68.3)$ & $26(60.5)$ \\
\hline $95 \% \mathrm{Cl}$ & $32.5-63.9$ & $69.7-95.2$ & $62.4-89.4$ & $51.9-81.9$ & $3.0-25.4$ & $40.0-70.4$ & $51.9-81.9$ & $44.4-75.0$ \\
\hline \multicolumn{9}{|l|}{ Cured children according to sex } \\
\hline Male & $6(31.6)$ & $14(46.7)$ & $19(59.4)$ & $10(35.7)$ & $1(25.0)$ & $9(36.0)$ & $13(46.4)$ & $9(34.6)$ \\
\hline $95 \% \mathrm{Cl}$ & $12.5-56.6$ & $28.3-65.7$ & $40.6-76.3$ & $18.6-55.9$ & $0.6-80.6$ & $18.0-57.5$ & $27.5-66.1$ & $17.2-55.7$ \\
\hline Female & $13(68.4)$ & $16(53.3)$ & $13(40.6)$ & $18(64.3)$ & $3(75.0)$ & $16(64.0)$ & $15(53.6)$ & $17(65.4)$ \\
\hline $95 \% \mathrm{Cl}$ & $43.4-87.4$ & $34.3-71.7$ & $23.7-59.4$ & $44.1-81.4$ & 19.4-99.4 & $42.5-82.0$ & $33.9-72.5$ & $44.3-82.8$ \\
\hline Cured children with light infection & $19 / 40(47.5)$ & 29/33 (87.9) & 28/35 (80.0) & $27 / 37(73.0)$ & $4 / 26(15.4)$ & $24 / 34(70.6)$ & 26/33 (78.8) & 23/32 (71.9) \\
\hline Cured children with heavy infections (\%) & $0 / 6(0)$ & $1 / 2(50.0)$ & $4 / 6(66.7)$ & $1 / 4(25.0)$ & $0 / 11(0.0)$ & $1 / 11(9.1)$ & 2/8 (25.0) & $3 / 11(27.3)$ \\
\hline \multicolumn{9}{|l|}{ Geometric mean eggs/10 mL of urine } \\
\hline Before treatment & 7.8 & 7.5 & 8.4 & 8.3 & 31.5 & 21.6 & 16.6 & 17.2 \\
\hline After treatment & 2.4 & 0.1 & 0.2 & 0.3 & 13.1 & 0.5 & 0.2 & 0.4 \\
\hline Egg reduction rate & 68.9 & 98.3 & 97.6 & 96.5 & 58.5 & 97.6 & 98.6 & 97.6 \\
\hline$(95 \% \mathrm{Cl})$ & $46.6-83.6$ & $95.4-99.8$ & $94.9-99.2$ & $93.1-98.7$ & $38.7-71.4$ & $96.4-98.6$ & $97.7-99.3$ & $95.3-98.9$ \\
\hline \multicolumn{9}{|l|}{ Arithmetic mean eggs/10 mL of urine } \\
\hline Before treatment & 22.7 & 14.3 & 21.7 & 16.9 & 94.4 & 89.5 & 31.0 & 34.4 \\
\hline After treatment & 11.5 & 0.3 & 0.4 & 0.9 & 49.0 & 1.2 & 0.4 & 1.0 \\
\hline Egg reduction rate & 49.5 & 97.8 & 98.2 & 94.5 & 46.9 & 98.7 & 98.8 & 97.0 \\
\hline$(95 \% \mathrm{Cl})$ & $0.2-77.3$ & $93.6-99.9$ & $96.1-99.5$ & $85.7-99.1$ & $36.4-77.6$ & $96.7-99.3$ & $97.7-99.5$ & $92.9-99.2$ \\
\hline
\end{tabular}

${ }^{a}$ Range 34.6-44.1 excluding the wrongly dosed child

${ }^{\mathrm{b}}$ Range 36.4-42.9 excluding the wrongly dosed child

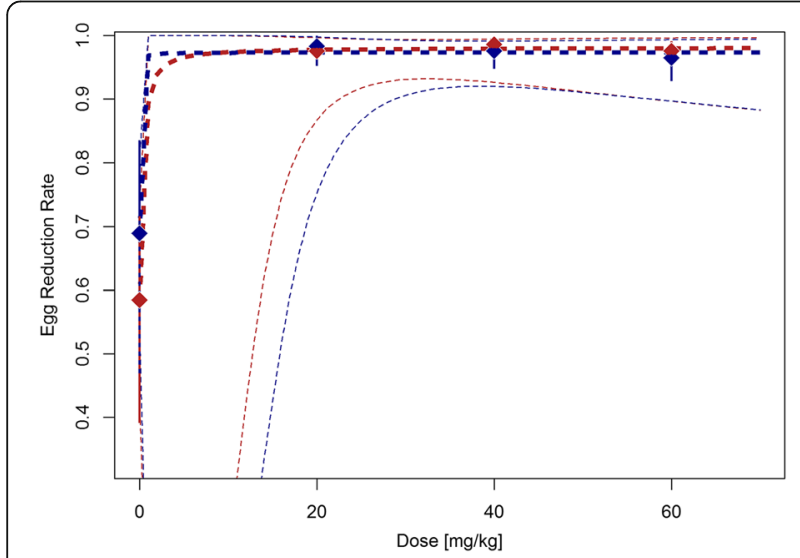

Fig. 3 Egg reduction rates in PSAC (blue lines) and SAC (red lines). Diamonds show observed cure rates with 95\% Cls (vertical lines). Dashed lines represent the estimated dose-response curve and corresponding $95 \% \mathrm{Cl}$ predicted by the $\mathrm{E}_{\max }$ model with S. haematobium. Our results build on an earlier dose-finding study in S. mansoni-infected children [24].

Several findings of our study are worth highlighting. First, the highest overall CRs among PSAC (85.7\%) and SAC (68.3\%) were obtained with $20 \mathrm{mg} / \mathrm{kg}$ and $40 \mathrm{mg} /$ $\mathrm{kg}$ praziquantel, respectively and not with the highest dose administered, $60 \mathrm{mg} / \mathrm{kg}$. For both age groups, CRs revealed even a slight inverse dose-rate effect. Similarly, ERRs increased very fast up to $98 \%$ and did not increase further regardless of the praziquantel dose administered. Interestingly, $60 \mathrm{mg} / \mathrm{kg}$ praziquantel also showed lower CRs in PSAC with moderate/high S. haematobium infection intensities compared to the two lower doses. For example, the CR in PSAC characterised by heavy infection intensities treated with $60 \mathrm{mg} / \mathrm{kg}$ praziquantel was as low as $25 \%$. However, only a handful of PSAC suffered from moderate and high infection intensities; hence, no clear picture can be drawn for this age group. In SAC similar CRs were observed in children harbouring heavy infection intensities treated with 40 and $60 \mathrm{mg} / \mathrm{kg}$. In summary, a high dose of praziquantel seems to have no additional benefit in the treatment of S. haematobium infections. This result is in contrast with our recent 
Table 3 Main type of clinical symptoms (number and percentage) before treatment and adverse events 3 and 24 h after praziquantel administration in Schistosoma haematobium-infected preschool-aged children $(n=168)$ and school-aged children $(n=173)$

\begin{tabular}{|c|c|c|c|c|c|c|c|c|c|c|}
\hline \multirow[b]{2}{*}{ Symptoms } & \multicolumn{5}{|c|}{ Preschool-aged children (PSAC) ${ }^{a}$} & \multicolumn{5}{|c|}{ School-aged children $(S A C)^{b}$} \\
\hline & $\begin{array}{l}\text { Placebo } \\
(n=41)\end{array}$ & $\begin{array}{l}20 \mathrm{mg} / \mathrm{kg} \\
(\mathrm{n}=40)\end{array}$ & $\begin{array}{l}40 \mathrm{mg} / \mathrm{kg} \\
(\mathrm{n}=44)\end{array}$ & $\begin{array}{l}60 \mathrm{mg} / \mathrm{kg} \\
(n=43)\end{array}$ & $\begin{array}{l}\text { Overall } \\
(n=168)\end{array}$ & $\begin{array}{l}\text { Placebo } \\
(n=38)\end{array}$ & $\begin{array}{l}20 \mathrm{mg} / \mathrm{kg} \\
(n=45)\end{array}$ & $\begin{array}{l}40 \mathrm{mg} / \mathrm{kg} \\
(n=46)\end{array}$ & $\begin{array}{l}60 \mathrm{mg} / \mathrm{kg} \\
(n=44)\end{array}$ & $\begin{array}{l}\text { Overall } \\
(n=173)\end{array}$ \\
\hline \multicolumn{11}{|l|}{ Before treatment } \\
\hline Moderate & $0(0.0)$ & $0(0.0)$ & $0(0.0)$ & $0(0.0)$ & $0(0.0)$ & $0(0.0)$ & $0(0.0)$ & $0(0.0)$ & $0(0.0)$ & $0(0.0)$ \\
\hline Mild & $24(58.5)$ & $19(47.5)$ & $26(59.1)$ & $19(44.2)$ & $88(52.4)$ & $20(52.6)$ & $26(57.8)$ & $25(54.3)$ & $21(47.7)$ & $92(53.2)$ \\
\hline None & $17(41.5)$ & $21(52.5)$ & $18(40.9)$ & $24(55.8)$ & $80(47.6)$ & $18(47.4)$ & $19(42.2)$ & $21(45.7)$ & $23(52.3)$ & $81(46.8)$ \\
\hline Fever & $6(14.1)$ & $3(7.5)$ & $7(15.9)$ & $5(11.6)$ & $21(12.5)$ & $5(13.2)$ & $7(15.6)$ & $5(10.9)$ & $6(13.6)$ & $23(13.3)$ \\
\hline Headache & $8(19.5)$ & $6(15.0)$ & $13(29.5)$ & $10(23.3)$ & $37(22.0)$ & $3(7.9)$ & $7(15.6)$ & $10(21.7)$ & $7(15.9)$ & $27(15.6)$ \\
\hline Nausea & $3(7.3)$ & $4(10.0)$ & $3(6.8)$ & $1(2.3)$ & $11(6.5)$ & $2(5.3)$ & $1(2.2)$ & $4(8.7)$ & $5(11.4)$ & $12(6.9)$ \\
\hline Vomiting & $1(2.4)$ & $1(2.5)$ & $1(2.3)$ & $2(4.7)$ & $5(3.0)$ & $0(0.0)$ & $0(0.0)$ & $1(2.2)$ & $0(0.0)$ & $1(0.6)$ \\
\hline Diarrhoea & $4(9.6)$ & $4(10.0)$ & $4(9.1)$ & $5(11.6)$ & $17(10.1)$ & $0(0.0)$ & $1(2.2)$ & $3(6.5)$ & $2(4.5)$ & $6(3.5)$ \\
\hline Dizziness & $2(4.9)$ & $0(0.0)$ & $0(0.0)$ & $0(0.0)$ & $2(1.2)$ & $0(0.0)$ & $0(0.0)$ & $0(0.0)$ & $0(0.0)$ & $0(0.0)$ \\
\hline Stomach ache & $2(4.9)$ & $5(12.5)$ & $8(18.2)$ & $4(9.3)$ & $19(11.3)$ & $1(2.6)$ & $6(13.3)$ & $6(13.0)$ & $4(9.1)$ & $17(9.8)$ \\
\hline \multicolumn{11}{|l|}{$3 \mathrm{~h}$ post-treatment } \\
\hline Moderate & $0(0.0)$ & $0(0.0)$ & $0(0.0)$ & $1(2.3)$ & $1(0.6)$ & $1(2.6)$ & $2(4.4)$ & $4(8.7)$ & $5(11.4)$ & $12(6.9)$ \\
\hline Mild & $6(14.6)$ & $8(20.0)$ & $15(34.1)$ & $23(53.5)$ & $52(31.0)$ & $18(47.4)$ & $23(51.1)$ & $21(45.7)$ & $26(59.1)$ & $88(50.9)$ \\
\hline None & 35 (85.4) & $32(80.0)$ & $29(65.9)$ & $19(44.2)$ & $115(68.5)$ & $19(50.0)$ & $20(44.4)$ & $21(45.7)$ & $13(29.5)$ & $73(42.2)$ \\
\hline Fever & $3(7.3)$ & $3(7.5)$ & $2(4.5)$ & $4(9.3)$ & $12(7.1)$ & $6(15.8)$ & $4(8.9)$ & $8(17.4)$ & $12(27.3)$ & $30(17.3)$ \\
\hline Headache & $1(2.4)$ & $2(5.0)$ & $1(2.3)$ & $7(16.3)$ & $11(6.5)$ & $8(21.1)$ & $10(22.2)$ & $6(13.0)$ & $6(13.6)$ & $30(17.3)$ \\
\hline Nausea & $1(2.4)$ & $1(2.5)$ & $4(9.1)$ & $5(11.6)$ & $11(6.5)$ & $4(10.5)$ & $3(6.7)$ & $9(19.6)$ & $14(31.8)$ & $30(17.3)$ \\
\hline Vomiting & $0(0.0)$ & $1(2.5)$ & $3(6.8)$ & $9(20.9)$ & $13(7.7)$ & $1(2.6)$ & $3(6.7)$ & $8(17.4)$ & $10(22.7)$ & $22(12.7)$ \\
\hline Diarrhoea & $0(0.0)$ & $1(2.5)$ & $1(2.3)$ & $3(7.0)$ & $5(3.0)$ & $3(7.9)$ & $3(6.7)$ & $2(4.3)$ & $0(0.0)$ & $8(4.6)$ \\
\hline Dizziness & $1(2.4)$ & $1(2.5)$ & $2(4.5)$ & $4(9.3)$ & $8(4.8)$ & $5(13.2)$ & $4(8.9)$ & $8(17.4)$ & $5(11.4)$ & $22(12.7)$ \\
\hline Stomach ache & $3(7.3)$ & $4(10.0)$ & $4(9.1)$ & $2(4.7)$ & $13(7.7)$ & $5(13.2)$ & $11(24.4)$ & $9(19.6)$ & $12(27.3)$ & $37(21.4)$ \\
\hline \multicolumn{11}{|c|}{24 h post-treatment } \\
\hline Moderate & $0(0.0)$ & $0(0.0)$ & $0(0.0)$ & $0(0.0)$ & $0(0.0)$ & $0(0.0)$ & $0(0.0)$ & $0(0.0)$ & $0(0.0)$ & $0(0.0)$ \\
\hline Mild & $4(9.6)$ & $7(17.5)$ & $8(18.2)$ & $6(14.0)$ & $25(14.9)$ & $12(31.6)$ & $12(26.7)$ & $12(26.1)$ & $11(25.0)$ & $47(27.2)$ \\
\hline None & $37(90.2)$ & $33(82.5)$ & $36(81.8)$ & $37(86.0)$ & $143(85.1)$ & $26(68.4)$ & $33(73.3)$ & $34(73.9)$ & $33(75.0)$ & $126(72.8)$ \\
\hline Fever & $2(4.9)$ & $4(10.0)$ & $2(4.5)$ & $2(4.7)$ & $10(6.0)$ & $5(13.2)$ & $7(15.6)$ & $5(10.9)$ & $6(13.6)$ & $23(13.3)$ \\
\hline Headache & $1(2.4)$ & $1(2.5)$ & $1(2.3)$ & $2(4.7)$ & $5(3.0)$ & $3(7.9)$ & 7 (15.6) & $10(21.7)$ & $7(15.9)$ & 27 (15.6) \\
\hline Nausea & $1(2.4)$ & $0(0.0)$ & $0(0.0)$ & $3(7.0)$ & $4(2.4)$ & $2(5.3)$ & $1(2.2)$ & $4(8.7)$ & $5(11.4)$ & $12(6.9)$ \\
\hline Vomiting & $0(0.0)$ & $0(0.0)$ & $0(0.0)$ & $3(7.0)$ & $3(1.8)$ & $0(0.0)$ & $0(0.0)$ & $1(2.2)$ & $0(0.0)$ & $1(0.6)$ \\
\hline Diarrhoea & $1(2.4)$ & $2(5.0)$ & $5(11.4)$ & $0(0.0)$ & $8(4.8)$ & $0(0.0)$ & $1(2.2)$ & $3(6.5)$ & $2(4.5)$ & $6(3.5)$ \\
\hline Dizziness & $1(2.4)$ & $0(0.0)$ & $0(0.0)$ & $1(2.3)$ & $1(0.6)$ & $0(0.0)$ & $0(0.0)$ & $0(0.0)$ & $0(0.0)$ & $0(0.0)$ \\
\hline Stomach ache & $2(4.9)$ & $0(0.0)$ & $2(4.5)$ & $2(4.7)$ & $6(3.6)$ & $1(2.6)$ & $6(13.3)$ & $6(13.0)$ & $4(9.1)$ & $17(9.8)$ \\
\hline
\end{tabular}

2 children were absent (placebo $(n=1)$ and $60 \mathrm{mg} / \mathrm{kg}(n=1)$ ) following treatment and were not assessed for adverse event

$\mathrm{b}_{1}$ child was absent $(20 \mathrm{mg} / \mathrm{kg}$ treatment arm) following treatment and was not assessed for adverse events

study, where we reported that in SAC infected with $S$. mansoni, CRs increased with higher doses of praziquantel [24], while only moderate CRs were observed in PSAC at all doses administered.

Overall higher CRs were observed in PSAC (68-86\%) when compared to SAC (56-68\%), which mirrors a recent meta-analysis by Zwang et al., where $40 \mathrm{mg} / \mathrm{kg}$ praziquantel cured $87.3 \%$ of $S$. haematobium-infected
PSAC compared to $71.4 \%$ of SAC [34]. Nonetheless, our finding can most likely be explained with the lower infection intensities present in PSAC, as CRs in children characterised by heavy infection intensities were low. Hence, our results confirm the relationship between CRs and infection intensity observed in previous studies [35, 36]. Overall, the results emphasise the need for rigorous treatment programmes in settings with heavy infection 
of $S$. haematobium, since reductions in egg output significantly correlated with decreased morbidity [37, 38].

No dose-response relationship was observed for ERRs in both age groups above $20 \mathrm{mg} / \mathrm{kg}$. This finding is in line with an earlier meta-analysis by Zwang et al. [34] which found no significant relationship for dose and ERR for any of the Schistosoma species. However, our dose-finding study in $S$. mansoni-infected children showed that higher ERRs (based on GMs) were observed in children treated with 40 and $60 \mathrm{mg} / \mathrm{kg}$ compared to $20 \mathrm{mg} / \mathrm{kg}$ [24]. Recent WHO Standard Operating Procedures have set a threshold of a 90\% ERR based on AM for clinical efficacy and recommend that control programmes should investigate drug performance in populations where the ERR is lower [39]. Regardless of age group and whether GM or AM was used to determine ERRs, we found that all praziquantel doses used against $S$. haematobium, in contrast to preschoolers infected with S. mansoni [24], yielded ERRs above 90\%. Despite the excellent efficacy of $20 \mathrm{mg} / \mathrm{kg}$ of praziquantel against light $S$. haematobium infections in this study, the use of two different doses, namely $20 \mathrm{mg} / \mathrm{kg}$ for $S$. haematobium and $40 \mathrm{mg} / \mathrm{kg}$ for $S$. mansoni in settings where Schistosoma species are overlapping, would raise logistical and operational challenges since control programmes are acting at large-scale levels such as district or country levels. Therefore, rigorous cost-effectiveness studies need to be implemented before a change of treatment guidelines could be considered. However, at a point-of-care level, using a test-and-treat approach, $20 \mathrm{mg} / \mathrm{kg}$ and $40 \mathrm{mg} / \mathrm{kg}$ could be recommended to treat PSAC for $S$. haematobium and S. mansoni infections, respectively.

In PSAC we observed a high CR in the placebo arm similar to what was observed in our S. mansoni study [24]. The probability of being cured for placebo-treated children was particularly high in children with low egg loads despite using a relatively strong diagnostic approach at baseline and follow-up by collecting per child three consecutive urine samples for each time point (baseline and follow-up). On the other hand, no cured individual was observed in placebo-treated children with heavy infection intensity at baseline. The high CR observed in the placebo treatment arm among PSAC was thus likely reflective of the low sensitivity of the urine filtration method for light infections [40, 41]. Our findings underscore the value of adding a placebo group in Schistosoma drug efficacy trials-the overestimation of CRs due to potential false negatives in light infections is visible. More importantly, our observations emphasise the need for Schistosoma species-related standard operating procedures including reliable diagnostic tools, suitable for drug efficacy assessment for low infection intensities [40-42].
With regard to safety outcomes, the main adverse events observed in both PSAC and SAC are in line with the adverse events reported in previous studies [16, 24, 34]. We observed an increase of adverse events severity that was proportional to praziquantel dose in SAC, while only one child showed moderate diarrhoea at the $60 \mathrm{mg} / \mathrm{kg}$ treatment dose in PSAC. However, as mentioned earlier, the accuracy of the adverse event severity assessment in PSAC is questionable, in particular for the less visible mild adverse events, since the reporting is done by the children's mothers.

\section{Conclusions}

Praziquantel showed a high response rate in PSAC and SAC infected with $S$. haematobium, with high efficacy observed already at $20 \mathrm{mg} / \mathrm{kg}$, particularly in light infections. No benefit was observed using higher praziquantel doses in the current study. However, to be able to provide ultimate dosing recommendations of praziquantel for PSAC, additional studies might be required to support our conclusions, including pharmacokinetic studies and studies in PSAC suffering from moderate and heavy S. haematobium infections.

\section{Additional file}

Additional file 1: Table S1. Imputation on cure rates of individuals lost after treatment in 20, 40 and $60 \mathrm{mg} / \mathrm{kg}$ praziquantel and placebo treatment arms among Schistosoma haematobium-infected preschool-aged children and school-aged children (intention-to-treat). Figure S1. E $_{\max }$ model predicting cure rates (CRs) based on actual doses in preschool-aged children (blue symbols) and school-aged children (red symbols). Figure S2. Predicted probability of being cured by baseline infection intensity in preschool children (blue lines) and school-aged children (red lines). (DOCX $231 \mathrm{~kb}$ )

\section{Abbreviations}

AM: Arithmetic mean; CR: Cure rate; ERR: Egg reduction rate; GM: Geometric mean; PSAC: Preschool-aged children; SAC: School-aged children; WHO: World Health Organization

\section{Acknowledgements}

We are grateful to all participating children and their parents. We thank the mothers of the PSAC from the study of all five villages and the teachers from Mopé and Nyan for their support. Moreover, we are thankful to our staff of doctors, nurses, technicians, volunteers and drivers, whose expertise and dedication were indispensable. We are grateful to the European Research Council for financial support. This work was supported by the donation of Cesol $^{\circledR}$ tablets provided by Merck KGaA, Darmstadt, Germany.

\section{Funding}

This work was supported by the European Research Council (grant number ERC-2013-CoG 614739-A_HERO).

\section{Availability of data and materials}

The datasets supporting the conclusions of this article are included within the article.

\section{Authors' contributions}

JTC, JH and JK designed the study; JTC, GP, RBY, YKN, BB, JK and JKo conducted the study; JTC, JH and JK analysed and interpreted the data; JTC and JK wrote the first draft of the manuscript; GP, RBY, BB, YKN and JH revised the manuscript. 
All authors read and approved the final version of the manuscript. Merck KGaA, Darmstadt, Germany reviewed the manuscript for medical accuracy only before journal submission. The authors are fully responsible for the content of this manuscript, and the views and opinions described in the publication reflect solely those of the authors.

\section{Ethics approval and consent to participate}

Approval was obtained by the Comité d'Ethique et de la Recherche of the Ministry of Health in Côte d'Ivoire (CNER, reference no. 037/MSLS/CNER-dkn) and the Ethical Committee of Northwestern and Central Switzerland (EKNZ, reference no. 162/2014)

Information provided to communities and written informed consent and assent procedures were conducted as described elsewhere [24]

\section{Consent for publication}

Consent to publish from the participant (or legal parent or guardian for children) to report individual patient data was obtained.

\section{Competing interests}

The authors declare that they have no competing interests.

\section{Publisher's Note}

Springer Nature remains neutral with regard to jurisdictional claims in published maps and institutional affiliations.

\section{Author details \\ ${ }^{1}$ Department of Medical Parasitology and Infection Biology, Swiss Tropical and Public Health Institute, P.O. Box, CH-4002, Basel, Switzerland. ${ }^{2}$ University of Basel, Basel, Switzerland. ${ }^{3}$ Unité de Formation et de Recherche Biosciences, Université Félix Houphouët-Boigny, Abidjan, Côte d'Ivoire. ${ }^{4}$ Centre Suisse de Recherches Scientifiques, Abidjan, Côte d'Ivoire. ${ }^{5}$ Departement d'Agboville, Centre de Santé Urbain d'Azaguié, Azaguié, Côte d'Ivoire. ${ }^{6}$ Department of Epidemiology and Public Health, Swiss Tropical and Public Health Institute, Basel, Switzerland.}

\section{Received: 10 November 2017 Accepted: 1 May 2018} Published online: 01 June 2018

\section{References}

1. Steinmann P, Keiser J, Bos R, Tanner M, Utzinger J. Schistosomiasis and water resources development: systematic review, meta-analysis, and estimates of people at risk. Lancet Infect Dis. 2006;6:411-25.

2. King CH. Parasites and poverty: the case of schistosomiasis. Acta Trop. 2010; 113:95-104.

3. Gryseels B, Polman K, Clerinx J, Kestens L. Human schistosomiasis. Lancet. 2006:368:1106-18.

4. Colley DG, Bustinduy AL, Secor WE, King CH. Human schistosomiasis. Lancet. 2014 ;383(9936):2253-64.

5. Utzinger J, Raso G, Brooker S, De Savigny D, Tanner M, Ornbjerg N, Singer BH, N'Goran EK. Schistosomiasis and neglected tropical diseases: towards integrated and sustainable control and a word of caution. Parasitology. 2009:136:1859-74.

6. Gray DJ, Ross AG, Li YS, McManus DP. Diagnosis and management of schistosomiasis. BMJ. 2011;342:d2651.

7. King $\mathrm{CH}$, Dickman $\mathrm{K}$, Tisch DJ. Reassessment of the cost of chronic helmintic infection: a meta-analysis of disability-related outcomes in endemic schistosomiasis. Lancet. 2005;365:1561-9.

8. Jukes MC, Nokes CA, Alcock KJ, Lambo JK, Kihamia C, Ngorosho N, Mbise A, Lorri W, Yona E, Mwanri L, et al. Heavy schistosomiasis associated with poor short-term memory and slower reaction times in Tanzanian schoolchildren. Tropical Med Int Health. 2002;7:104-17.

9. Bhargava A, Jukes M, Lambo J, Kihamia CM, Lorri W, Nokes C, Drake L, Bundy D. Anthelmintic treatment improves the hemoglobin and serum ferritin concentrations of Tanzanian schoolchildren. Food Nutr Bull. 2003;24: 332-42

10. Hotez PJ, Bundy DAP, Beegle K, Brooker S, Drake L, de Silva N, Montresor A, Engels $D$, Jukes $M$, Chitsulo L, et al. Helminth infections: soil-transmitted helminth infections and schistosomiasis. In: Jamison DT, Breman JG, Measham AR, Alleyne G, Claeson M, Evans DB, Jha P, Mills A, Musgrove P, e, editors. Disease control priorities in developing countries. 2nd ed. Washington, DC:The World Bank; 2006.
11. World Health Organization. Preventive chemotherapy in human helminthiasis: coordinated use of anthelminthic drugs in control interventions: a manual for health professionals and programme managers. Geneva: WHO; 2006

12. Lelo AE, Mburu DN, Magoma GN, Mungai BN, Kihara JH, Mwangi IN, Maina GM, Kinuthia JM, Mutuku MW, Loker ES, et al. No apparent reduction in schistosome burden or genetic diversity following four years of schoolbased mass drug administration in Mwea, Central Kenya, a heavy transmission area. PLoS Negl Trop Dis. 2014;8:e3221.

13. Leenstra T, Coutinho HM, Acosta LP, Langdon GC, Su L, Olveda RM, McGarvey ST, Kurtis JD, Friedman JF. Schistosoma japonicum reinfection after praziquantel treatment causes anemia associated with inflammation. Infect Immun. 2006:74:6398-407.

14. Stothard JR, Gabrielli AF. Schistosomiasis in African infants and preschool children: to treat or not to treat? Trends Parasitol. 2007;23:83-6.

15. Stothard JR, Sousa-Figueiredo JC, Betson M, Bustinduy A, Reinhard-Rupp J. Schistosomiasis in African infants and preschool children: let them now be treated! Trends Parasitol. 2013;29:197-205.

16. Coulibaly JT, N'Gbesso YK, Knopp S, Keiser J, N'Goran EK, Utzinger J. Efficacy and safety of praziquantel in preschool-aged children in an area coendemic for Schistosoma mansoni and S. haematobium. PLoS Negl Trop Dis. 2012;6:e1917.

17. Coulibaly JT, N'Gbesso YK, N'Guessan NA, Winkler MS, Utzinger J, N'Goran EK. Epidemiology of schistosomiasis in two high-risk communities of south Cote d'Ivoire with particular emphasis on pre-school-aged children. Am J Trop Med Hyg. 2013;89:32-41.

18. World Health Organization: Report of a meeting to review the results of studies on the treatment of schistosomiasis in pre-school-age children. 1314 September 2010. Geneva, World Health Organization. 2010.

19. Garba A, Barkire N, Djibo A, Lamine MS, Sofo B, Gouvras AN, Bosque-Oliva E, Webster JP, Stothard JR, Utzinger J, Fenwick A. Schistosomiasis in infants and preschool-aged children: infection in a single Schistosoma haematobium and a mixed S. haematobium-S. mansoni foci of Niger. Acta Trop. 2010;115:212-9.

20. Olliaro PL, Vaillant M, Hayes DJ, Montresor A, Chitsulo L. Practical dosing of praziquantel for schistosomiasis in preschool-aged children. Tropical Med Int Health. 2013;18:1085-9.

21. Jule AM, Vaillant M, Lang TA, Guerin PJ, Olliaro PL. The schistosomiasis clinical trials landscape: a systematic review of antischistosomal treatment efficacy studies and a case for sharing individual participant-level data (IPD). PLoS Negl Trop Dis. 2016;10:e0004784.

22. Kearns GL, Abdel-Rahman SM, Alander SW, Blowey DL, Leeder JS, Kauffman RE. Developmental pharmacology - drug disposition, action, and therapy in infants and children. N Engl J Med. 2003;349:1157-67.

23. Fernandez E, Perez R, Hernandez A, Tejada P, Arteta M, Ramos JT. Factors and mechanisms for pharmacokinetic differences between pediatric population and adults. Pharmaceutics. 2011:3:53-72.

24. Coulibaly JT, Panic G, Silue KD, Kovac J, Hattendorf J, Keiser J. Efficacy and safety of praziquantel in preschool-aged and school-aged children infected with Schistosoma mansoni: a randomised controlled, parallel-group, doseranging, phase 2 trial. Lancet Glob Health. 2017;5:e688-98.

25. World Health Organisation. Prevention and control of schistosomiasis and soil-transmitted helminthiasis: report of a WHO expert committee. WHO Tech Rep Ser. 2002;912:1-57.

26. Plouvier S, Leroy J-C, Colette J. A propos d'une technique simple de filtration des urines dans le diagnostic de la bilharziose urinaire en enquête de masse. Med Trop (Mars) 1975; 35:229-230.

27. Katz N, Chaves A, Pellegrino J. A simple device for quantitative stool thicksmear technique in schistosomiasis mansoni. Rev Inst Med Trop Sao Paulo. 1972:14:397-400.

28. Olliaro PL, Vaillant MT, Belizario VJ, Lwambo NJ, Ouldabdallahi M, Pieri OS, Amarillo ML, Kaatano GM, Diaw M, Domingues AC, et al. A multicentre randomized controlled trial of the efficacy and safety of single-dose praziquantel at $40 \mathrm{mg} / \mathrm{kg}$ vs. $60 \mathrm{mg} / \mathrm{kg}$ for treating intestinal schistosomiasis in the Philippines, Mauritania, Tanzania and Brazil. PLoS Negl Trop Dis. 2011; 5:e1165.

29. Rollinson D, Knopp S, Levitz S, Stothard JR, Tchuem Tchuente LA, Garba A Mohammed KA, Schur N, Person B, Colley DG, Utzinger J. Time to set the agenda for schistosomiasis elimination. Acta Trop. 2013;128:423-40.

30. World Health Organisation. Schistosomiasis: number of people treated worldwide in 2013. Wkly Epidemiol Rec. 2015;90:25-32. 
31. Savioli L, Gabrielli AF, Montresor A, Chitsulo L, Engels D. Schistosomiasis control in Africa: 8 years after World Health Assembly Resolution 54.19. Parasitology. 2009;136:1677-81.

32. Lo NC, Addiss DG, Hotez PJ, King CH, Stothard JR, Evans DS, Colley DG, Lin W, Coulibaly JT, Bustinduy AL, et al. A call to strengthen the global strategy against schistosomiasis and soil-transmitted helminthiasis: the time is now. Lancet Infect Dis. 2017;17:e64-9.

33. World Health Organisation. Report of a meeting to review the results of studies on the treatment of schistosomiasis in preschool-age children. Geneva: World Health Organization; 2011.

34. Zwang J, Olliaro PL. Clinical efficacy and tolerability of praziquantel for intestinal and urinary schistosomiasis-a meta-analysis of comparative and non-comparative clinical trials. PLoS Negl Trop Dis. 2014;8:e3286.

35. Midzi N, Sangweme D, Zinyowera S, Mapingure MP, Brouwer KC, Kumar N, Mutapi F, Woelk G, Mduluza T. Efficacy and side effects of praziquantel treatment against Schistosoma haematobium infection among primary school children in Zimbabwe. Trans R Soc Trop Med Hyg. 2008;102:759-66.

36. Utzinger J, N'Goran EK, N'Dri A, Lengeler C, Tanner M. Efficacy of praziquantel against Schistosoma mansoni with particular consideration for intensity of infection. Tropical Med Int Health. 2000;5:771-8.

37. Andrade G, Bertsch DJ, Gazzinelli A, King CH. Decline in infection-related morbidities following drug-mediated reductions in the intensity of Schistosoma infection: a systematic review and meta-analysis. PLoS Negl Trop Dis. 2017;11:e0005372.

38. Barda B, Coulibaly JT, Hatz C, Keiser J. Ultrasonographic evaluation of urinary tract morbidity in school-aged and preschool-aged children infected with Schistosoma haematobium and its evolution after praziquantel treatment: A randomized controlled trial. PLoS Negl Trop Dis. 2017;11(2):e0005400.

39. WHO. Assessing the efficacy of anthelminthic drugs against schistosomiasis and soil-transmitted helminthiases. Geneva: World Health Organization; 2013.

40. McCarthy JS, Lustigman S, Yang GJ, Barakat RM, Garcia HH, Sripa B, Willingham AL, Prichard RK, Basanez MG. A research agenda for helminth diseases of humans: diagnostics for control and elimination programmes. PLoS Negl Trop Dis. 2012;6:e1601

41. Solomon AW, Engels D, Bailey RL, Blake IM, Brooker S, Chen JX, Chen $J \mathrm{H}$, Churcher TS, Drakeley CJ, Edwards T, et al. A diagnostics platform for the integrated mapping, monitoring, and surveillance of neglected tropical diseases: rationale and target product profiles. PLoS Negl Trop Dis. 2012;6:e1746.

42. Saathoff E, Olsen A, Magnussen P, Kvalsvig JD, Becker W, Appleton CC. Patterns of Schistosoma haematobium infection, impact of praziquantel treatment and re-infection after treatment in a cohort of schoolchildren from rural KwaZulu-Natal/South Africa. BMC Infect Dis. 2004;4:40.

\section{Ready to submit your research? Choose BMC and benefit from:}

- fast, convenient online submission

- thorough peer review by experienced researchers in your field

- rapid publication on acceptance

- support for research data, including large and complex data types

- gold Open Access which fosters wider collaboration and increased citations - maximum visibility for your research: over $100 \mathrm{M}$ website views per year

At BMC, research is always in progress.

Learn more biomedcentral.com/submissions 